\title{
Freud and the "School of Helmholtz"
}

\author{
By Paul F. Cranefield, New York
}

The late Siegrried Bernfeld advanced the idea, in 1944, that Sigmund Freud had been significantly influenced by an extreme form of mechanistic materialism which Bernfeld called "the school of Helmholtz." "This idea, variously oversimplified, has assumed a firm place among an interesting group of myths which are embodied in the history of psychoanalysis. According to the extreme form of this particular myth, Freud was subjected to two conflicting forces, namely his allegiance to mechanistic and molecular explanation and his desire to forge a new way of looking at the mind, a psychological way free from the entanglements of narrow and naïve materialism.

We may well begin by remarking that there never was a "school of Helmholtz." There was a small group of physiologists who, early in their careers, asserted their conviction that the phenomena of life could be explained in mechanistic terms. The ideological leader of this group was Emil du Bois-Reymond, and his earliest disciple was Ernst BrücKe. To this group Helmholtz was a late comer, and although he did, with CARL Ludwig, Brücke, and du Bois-Reymond, make up those who were the founders of what I have called the biophysics movement of $1847,,^{2}$ he was not the leader of that movement, nor was it his "school." There is, indeed, something peculiarly misleading in the very phrase "school of Helmholtz" for the term implies a group of students and disciples and Helmholtz was a notoriously isolated figure who had remarkably few pupils or close associates either as a physiologist or as a physicist.

Apart from the unfortunate use of the term "school of Helmholtz" there are more serious errors in Bernfeld's identification and especially in the subsequent use of it by others. ${ }^{3}$ For one thing the extreme mechanistic

1 S.Bernfeld, Freud's Earliest Theories and the School of Helmholtz, Psychoanal.Quart. 13 (1944) 341-362; also, Freud's Scientific Beginnings, Amer. Imago 6 (1949) 163-196.

2 P.F. Cranefield, The Organic Physics of 1847 and the Biophysics of Today, J. Hist. Med.12 (1957) 407-423.

${ }^{3}$ Bernfeld himself had a reasonably balanced view of the biophysical group of 1847 and was aware of its links to the Naturphilosophie movement which it seemed so adamantly to oppose. Apart from his unfortunate choice of the phrase «the school of Helmholtz » his paper was a significant and useful contribution to the history of psychoanalysis. Indeed, his 
materialists of the mid-19th century, those who gave the phrase its connotation of agnosticism and naive reductionism, were not part of the biophysics group of 1847 at all. The representative figures of the extreme materialistic movement were KARL Vogt and F.K.C.L.Büchner, who had no direct connection with the 1847 biophysical group. If Freud was influenced by that school of extreme materialists it was not because he was a pupil of Brücke.

A second difficulty arises when we consider the fact that Freud was born in 1856, at which time the initial fervor of the biophysics movement had already waned a little, and did not begin to study medicine, or even biology, until a time when the self-confident mechanism of the 1847 movement had nearly died. As I have shown elsewhere ${ }^{2,4}$ there was little left of the mechanistic approach in the researches of Brücke and Ludwig by 1874 . The following quotation from a lecture given by Adolph FicK in 1874 is to the point: ${ }^{5}$ "... the absolute dominance of the mechanistic-mechanical orientation in physiology has proved to be an Icarus flight." Fick added that many workers who were strongly oriented toward the physical approach in 1850 had by 1874 turned to other methods such as those of

papers on the subject, too few in number, were distinguished and were among the earliest efforts to examine the history of psychoanalysis in objective and scholarly terms and in doing so, to rely heavily upon primary sources. - A recent cautious, sceptical and well balanced appraisal of Bernstein's proposition will be found in David SHaKow and DAvid Rapaport, The Influence of Freud on American Psychology, Psychological Issues, vol. 4, no. 1 (whole no. 13), International Universities Press, New York 1965. Those authors point out the important fact that a naïvely mechanistic approach did not become entrenched in psychoanalysis but did become entrenched in academic psychology and thereby gave rise to the sterile «scientism " which for so long vitiated much academic psychology and deflected it from a concern with the higher mental functions. Rather less critical reliance on the concept of the «school of Helmholtz » can be found in ERNEST Jones, The Life and Work of Sigmund Freud, vol. 1, Basic Books, New York 1953; in Peter Amacher, Freud's Neurological Education and its Influence on Psychoanalytic Theory, Psychological Issues, vol. 4, no. 4 (whole no. 16), International Universities Press, New York 1965; and in R.R. Holt, A Review of Some of Freud's Biological Assumptions and Their Influence on his Theories, in Psychoanalysis and Current Biological Thought, N.S. Greenfield and William C.Lewis, eds., University of Wisconsin Press, Madison 1965, pp. 93-124.

4 P.F. Cranefield, The Nineteenth Century Prelude to Modern Biophysics, Proceedings of the First National Biophysics Conference, Yale University Press, New Haven 1959, pp. 19-26.

5 AdolPh Fick, Methoden und Richtung der physiologischen Forschung, reprinted in AdoLPH Fick, Gesammelte Schriften, Stahel, Würzburg 1904, vol. 4, pp. 389 ff. 
histology, and he concluded that because of the great difficulty of the method it can be no surprise if "it is no more as generally taken up as it was in the time when it added the stimulus of novelty to the attractive force which it must always exert over logical minds."

A further difficulty centers around the fact that Freud was never a physiologist. It is true that Freud worked for a time in Brücke's laboratory, but in the 19th century physiology embodied two disciplines which are now distinct, namely physiology and histology. Freud's work under Brücke was histological in nature. It is certainly true that Freud was profoundly influenced by Brücke and probably was under the sway of Brücke's views about the nature of life and of scientific explanation, but there is nothing to suggest that Freud was ever involved in a sustained effort to explain a physiological phenomenon in mechanistic terms. Indeed, there is little to suggest that Freud ever did any physiological research at all. We may note in passing that Freud was deeply influenced by one of the most brilliant and profound experimental neurophysiologists of the 19 th century, namely Joseph Breuer. It is interesting that there is little or no evidence that Breuer was ever deeply involved in the philosophical debates over the role of mechanism in physiology.

Finally we should note that an oversimplified view of the "school of Helmholtz" somehow gives the impression that its members devoted themselves solely to the study of molecular mechanisms and ruthlessly excluded from their interests any of the more complex phenomena of the mind or spirit. The four members of the biophysics group of 1847 were in fact men of wide interests. I have shown elsewhere ${ }^{6}$ that those of them who were pupils of Johannes Müller (namely du Bois-Reymond, Brücke and Helmholtz) carried forward into their own careers Müller's deep interests in mental processes, in art, in sensory physiology and in perception.

I may also cite here a few excerpts from Ludwig's Lehrbuch of 1852 on the subject of dreams. ${ }^{7}$ Ludwig's Lehrbuch was indeed ruthlessly mechanistic in its approach to those areas of physiology which could be handled in mechanistic terms and it appeared at the peak of the mechanistic self-

6 P.F. Cranefield, The Philosophical and Cultural Interests of the Biophysics Movement of 1847, J.Hist.Med. 8 (1966) 1-7.

7 Carl Ludwig, Lehrbuch der Physiologie des Menschen, Winter, Heidelberg 1852, vol.1, pp.456-458. In this section on dreams LuDwig indicates that he followed the ideas of that most fascinating of all the early 19th century "psychologists, » J.E. PURKInJE. 
confidence of the 1847 biophysicists. Yet on the subject of dreams what do we read? That dreams are of several kinds. In one kind the reciprocity between the sensory nerves and the mind is suspended, while the mind retains its ability to create thought and to influence the muscles; this sort of dream is found in sleepwalking and sleeptalking. In a second sort of dream the reciprocity between the mind and the motor nerves is lost so that the function of movement is impaired, but the connections between the mind and the sensory nerves remain unimpaired. In such dreams an unpleasant sensation, such as pressure from clothing, will be attributed to the correct spot but will give rise to different thoughts and be explained as the result of different causes than those which would occur in response to the same stimulus during the waking state. In a third sort of dream the mind is loosened from its connections to both the motor and the sensory systems but retains its ability to create thought. We must not suppose that there is any physiological change in the nervous system to account for this, because we can show that the motor and sensory systems are intact and functioning. The iris, e.g., will constrict when light is flashed upon the eye, and a soft stroking of the palm of the hand will result in a movement of the hand or arm. In this form of dreaming the higher mental functions, though active, are very different from those seen in the waking state. The images of sensory objects take on the quality of hallucinations so that we believe we actually see, hear, feel or taste the objects or persons evoked in the dream. We lose the awareness that thought and imagination emanate from ourselves and we attribute our own thoughts to the imaginary visions of our dreams and often hear spiritually rich and apparently totally strange observations from the mouths of those visions. Moreover, the conclusions we arrive at in this sort of dream lack coherence, as if we had lost the concept of propositional logic. Finally, thoughts pass in rapid order, cannot be voluntarily fixed, seem to lack a goal, and disappear rapidly.

This passage from Ludwig, taken with the many examples I have given elsewhere ${ }^{6}$ from the work of Brücke, du Bois-Reymond and Helmholtz, surely indicate that a naïve and all pervading mechanistic materialism was not the sole characteristic of the biophysics group of 1847. Indeed, the very interests which characterized the Naturphilosophie movement continued to characterize its heirs (even though they were in formal revolt against it). It is paradoxical but true that one source of the influence of Naturphilosophie over Freud was exactly the "mechanistic" biophysics of 1847. 
Thus we see that the biophysics movement of 1847 was not the "school of Helmholtz"; that it was not part of the extremist wing of the mechanistic materialists; that it had lost much of its evangelical fervor by the 1870 's; and that it carried within itself a strong interest in the phenomena of the higher mental functions. On the other hand, as I have shown, ${ }^{2,4}$ one of the great contributions of the 1847 group was their conviction, for which they won general acceptance, that the phenomena of life are lawful and that the laws which govern them can be ascertained by experiment. As Professor E.H.Ackerknecht has pointed out to me, Freud did adhere to this conviction and in all of his writings from the earliest to the latest, he strove to order his assertions in a logical framework and to give evidence for his conclusions. Freud's belief in psychic determinism may well owe much to the determinism of his teachers and especially to Brücke. ${ }^{8}$ Beyond that, the "school of Helmholtz" deserves a long vacation and a careful reevaluation before it is forced to labor once again in the vineyards of the history of psychoanalysis.

\section{Acknowledgment}

I should like to thank Professor E. H. ACKerKnecht not only for many valuable discussions on the subject of this paper but for his having stimulated my interest in the history of medicine nearly 20 years ago and for his having continuously encouraged it since that time.

8 Shakow and Rapaport (1.c., note 4 supra) point out that DU Bors-Reymond had allowed not only for physico-chemical forces but also for new forces «equal in dignity » to the physico-chemical forces and that FREUD may well have looked on it in exactly that way. Their evaluation of the role played by the biophysics movement in influencing FreUd is judicious and convincing. 